\title{
As vozes do discurso indireto livre em tradução
}

\author{
Cecília Fischer Dias* \\ Karina de Castilhos Lucena**
}

\begin{abstract}
Resumo
Neste trabalho, analisamos Disgrace, de J. M. Coetzee, e sua tradução para o português brasileiro, Desonra, de José Rubens Siqueira. O romance é escrito basicamente em inglês (ou em português, na tradução), usando, também, termos e trechos em outros idiomas. Essas ocorrências são o foco na análise, e as consideramos como itens culturalmente marcados, conforme a proposta de Aixelá (1996). Mais especificamente, observamos, dentre as estratégias usadas para a tradução desses itens, as notas intratextuais. A partir disso, buscamos entender o efeito do acréscimo dessas notas no discurso indireto livre, considerando, com base em Wood (2012), que, quando há explicações que seriam óbvias para o personagem no discurso indireto livre, a tensão entre a voz do narrador e a do personagem se desfaz, e a voz do narrador se sobressai. Além disso, a ideia de que as explicações separam as vozes em tensão no discurso indireto livre leva à reflexão sobre a proposta de Moretti (2000) de que o romance na periferia da literatura mundial seria uma conciliação entre enredo estrangeiro, personagens locais e voz narrativa local. Observamos que a aproximação da proposta de Wood (2012) complexifica a de Moretti (2000), acrescentando um novo vetor ao triângulo: uma voz da tradução.
\end{abstract}

Palavras-chave: Tradução literária. Literatura multilíngue. Itens culturalmente marcados. Narrador. Romance.

\footnotetext{
* Universidade Federal do Rio Grande do Sul (UFRGS). Mestranda no Programa de Pós-graduação em Letras da Universidade Federal do Rio Grande do Sul. Tradutora e revisora na Terralíngua. ORCID: 0000-0001-7549-4912.

* Universidade Federal do Rio Grande do Sul (UFRGS). Doutora em Letras pela UFRGS. Professora do Instituto de Letras e do Programa de Pós-graduação em Letras da Universidade Federal do Rio Grande do Sul (UFRGS). ORCID: 0000-0001-5254-514X.
}

Cadernos CESPUC de Pesquisa. Série Ensaios. n.38, 10 Sem./2021, p. 46-62. e-ISSN: 2358-3231 (OJS). Recebido em: 21/06/2021. Aceito em: 09/09/2021. 


\title{
The Voices of Free Indirect Speech in Translation
}

\author{
Cecília Fischer Dias \\ Karina de Castilhos Lucena
}

\begin{abstract}
In this article, we analyze Disgrace" by J. M. Coetzee and its Brazilian Portuguese translation, Desonra, by José Rubens Siqueira. It is a novel written basically in English (or Portuguese, in the translation), which also uses terms and excerpts in other languages. These occurrences are the focus of this analysis, and we consider them as culture-specific items, according to Aixelá (1996). Specifically, we investigate, among the strategies used for translating these items, intratextual gloss. With that observation, we aim to understand the effect of the added gloss in free indirect speech, considering, based on Wood (2012), that, when there are explanations that would be obvious for the character in free indirect speech, the tension between the narrator's voice and that of the character is untied, and the narrator's voice comes forward. Moreover, the idea that explanations detach the voices in tension in free indirect speech leads to a reflection about Moretti's (2000) proposal that the novel in the periphery of world literature would be a compromise between foreign plot, local characters, and local narrative voice. We observed that taking Wood's (2012) approach into consideration, makes Moretti's (2000) proposal more complex, adding a third vector to the triangle: a translation voice.
\end{abstract}

Keywords: Literary translation. Multilingual literature. Culture-specific items. Narrator. Novel.

Cadernos CESPUC de Pesquisa. Série Ensaios. n.38, 10 Sem./2021, p. 46-62.

e-ISSN: 2358-3231 (OJS). Recebido em: 21/06/2021. Aceito em: 09/og/2021. 


\section{Introdução}

Neste trabalho, combinamos a leitura de Wood (2012) à de Moretti (2000) para entender o que a compreensão da proposta do primeiro autor, sobre a suspensão da tensão entre narrador e personagem pelo uso de explicações no discurso indireto livre, pode representar para proposta do segundo, de que o romance na periferia da literatura mundial seria uma conciliação entre enredo estrangeiro, personagens locais e voz narrativa local. Mais especificamente, observamos o papel da tradução nesse processo, em especial a tradução de textos que são compostos em mais de uma língua. Para isso, analisamos Disgrace, de J. M. Coetzee e Desonra, a tradução para o português brasileiro, de José Rubens Siqueira. O romance acompanha David Lurie, professor universitário que, após ser abusivo com uma de suas alunas, sai da cidade onde mora e vai para o campo, onde sua filha mora. A história é contada majoritariamente em inglês (e, na tradução, em português), mas usa termos e trechos em outras línguas. Para entender melhor esses termos e trechos, recorremos à noção de itens culturalmente marcados de Aixelá (1996). As ideias que orientam o trabalho, portanto, são: se o narrador é alguém que faz a mediação entre o contexto do romance e os leitores, ele provavelmente vai ter que explicar alguns aspectos; na tradução, haveria uma tendência a mais explicações; se, nesses momentos, o narrador se distancia do personagem, desfaz a tensão e se volta para o leitor, pode haver uma alteração no triângulo proposto por Moretti (2000) com essa suspensão da tensão do indireto livre.

\section{A conciliação}

Este texto tem como ideia central a de que o romance, na periferia da literatura mundial, é uma conciliação. Essa reflexão é apresentada por Franco Moretti, teórico literário italiano e fundador do Centro de Estudos do Romance na Universidade de Stanford, nos Estados Unidos. Em seu texto "Conjeturas sobre a literatura mundial", publicado em tradução para o português brasileiro em 2000, na revista Novos Estudos CEBRAP, 
Moretti (2000) apresenta um debate sobre a literatura mundial a partir de aproximações com a área da economia. Ele propõe que, para que se estude a literatura mundial, é preciso abrir mão da tradição do close reading, que demanda que se trabalhe com um cânone reduzido. Para trabalhar com a literatura mundial, é preciso trabalhar com leituras de "segunda mão", partindo das análises de outros pesquisadores, de forma a poder ter uma visão mais ampla. A conciliação é apresentada no texto não como um modelo, mas como um exemplo de combinação do que ele chama de distant reading e da literatura mundial.

Segundo ele, a literatura mundial seria um sistema uno e desigual, composto por uma relação de tensão entre centro e periferia. Nessa relação, as culturas centrais influenciam, ao mesmo tempo que ignoram, as periféricas. A partir da observação de estudos sobre o romance em diversos lugares e épocas (as leituras de "segunda mão"), Moretti formula que, na periferia, “[...] o romance moderno desponta não como um desenvolvimento autônomo, mas como uma conciliação entre uma influência formal ocidental (em geral francesa ou inglesa) e matérias locais." (MORETTI, 2000, p.177).

Com base nesses estudos, ele argumenta que, sendo essa conciliação tão presente, é ela, e não o caminho independente, a regra da ascensão do romance. Mas observa que, mesmo que seja a regra, a conciliação toma formas diferentes e que isso só mostra que o sistema é "[...] um sistema de variações. O sistema era uno, não uniforme." (MORETTI, 2000, p.178, grifos do autor). Por mais que o centro quisesse que o fosse, a matéria local é muito diversa.

Moretti então aprofunda a noção da conciliação, indicando que ela seria um triângulo: "[...] forma estrangeira, material local e forma local. Simplificando um pouco: enredo estrangeiro, personagens locais e ainda voz narrativa local [...]" (MORETTI, 2000, p. 178-179, grifos do autor) e que era justamente no aspecto narrativo que a instabilidade mais se mostrava. Ainda segundo o autor, essa instabilidade faz sentido, porque "[...] o narrador é o pólo de comentário, de explicação, de avaliação [...]" (MORETTI, 2000, p.179). O estrangeiro age sobre o "[...] ato de expressão do romance." (MORETTI, 2000, p.179, grifos do autor), mostrando que essa noção de sistema uno e desigual está na própria forma do romance. $\mathrm{E}$ 
é sobre este aspecto do narrador como agente de explicação que recai esta análise.

\section{O narrador}

Para pensar no narrador, é interessante partir do que James Wood, crítico inglês, professor de crítica literária na Universidade de Harvard, apresenta em Como funciona a fiç̧ão, de 2012. A obra trata de mais do que apenas a narração. É um livro em que o autor se propõe a abordar a técnica da literatura, mostrar como funciona a ficção, de forma prática. Está dividida em dez capítulos, cada um sobre um aspecto - entre eles, o que mais interessa aqui: a narração.

Nele, Wood (2012) começa dizendo que as possibilidades de narração são, na prática, limitadas à primeira pessoa e à terceira pessoa, já que, mesmo que haja a possibilidade de narrar em segunda pessoa do singular ou primeira do plural, por exemplo, ela seria uma opção mais próxima da poesia. O primeiro aspecto que ele aborda em relação à narração (em primeira ou em terceira pessoa) é o da confiabilidade, de que a narrativa em terceira pessoa, pela onisciência, seria mais confiável do que aquela em primeira pessoa.

Ele, então, inverte o pressuposto, dizendo que, "[n]a verdade, a narração em primeira pessoa costuma ser mais confiável que não confiável, e a narração 'onisciente' na terceira pessoa costuma ser mais parcial que onisciente." (WOOD, 2000 p.18). Ao tratar do narrador em terceira pessoa, argumenta que a "chamada onisciência é quase impossível." (WOOD, 2012, p.20), pois, quando se começa a contar uma história sobre um personagem, a tendência é de concentração em torno dele, como se quisesse se fundir com ele. Quando o narrador em terceira pessoa usa essa quase fusão é que temos o indireto livre, que vai ser o foco aqui.

Para abordar esse estilo, retomamos Moretti (2003), desta vez em "O século sério". Trata-se de um ensaio extraído de uma obra organizada por Moretti sobre o romance, sua evolução e expansão. A tradução do ensaio foi publicada também pela Novos Estudos CEBRAP, em 2003. 
Nele, o autor trata do desenvolvimento do que ele chama de estilo sério no romance europeu do século XIX, vinculando a seriedade à burguesia. Ele aponta que é aí que se estabelece a narração do cotidiano, por meio do que chama de "enchimentos". Essa narrativa cotidiana leva à referida seriedade. Não é mais necessário ter acontecimentos inesperados a todo momento. Essa questão é relacionada, também, à condição social: não é mais o trágico da aristocracia nem o cômico da plebe. É o sério da burguesia. Esse tipo de narrativa, de acordo com o autor, reflete a racionalização que ocorre na sociedade à época, de uma vida privada regular e ordenada.

Moretti traz ainda outras perspectivas da seriedade, mas aponta que há, também, uma tendência a uma descrição conservadora, que não estabelece limites entre a descrição física e o significado moral. A partir disso, Moretti indica que essa mistura de narração burguesa e descrição conservadora revela que o romance no século XIX representa "[...] um compromisso entre sistemas ideológicos diversos." (MORETTI, 2003, p.26, grifos do autor).

Essa ideia de compromisso é importante para este trabalho, pois é retomada adiante quando o autor discute o indireto livre. Segundo Moretti, esse estilo representa o compromisso social, que combina as subjetividades dos indivíduos com a impessoalidade da racionalização das relações sociais. Para ele, o indireto livre é a forma ideal para esse compromisso, pois

[...] deixa um espaço livre à voz individual (e um espaço variável, conforme as personagens e as circunstâncias: exatamente como sucede às pessoas de carne e osso no curso de sua socialização) mas ao mesmo tempo mistura e subordina a expressão individual ao tom abstrato e suprapessoal do narrador. E parece quase emergir uma terceira voz, uma voz intermediária e quase neutra [...] (MORETTI, 2003, p.29, grifos do autor)

Destacamos, aqui, dois aspectos. Em primeiro lugar, a ideia de que o indireto livre não é apenas um aspecto técnico: ele reflete relações sociais. No caso, o comportamento do protagonista de Disgrace/Desonra, David Lurie, como o individual, e a narrativa, como a racionalização, o que veremos em mais detalhe adiante.

Em segundo lugar, a de que essa quase neutralidade remete ao que Wood traz como o ponto alto desse tipo de discurso. Para o autor, o "estilo indireto livre atinge seu máximo quando é quase invisível ou inaudível [...]" (WOOD, 2012, p.22), quando nos faz questionar de quem são as palavras 
do texto. É esse estilo que nos permite acompanhar o que acontece pelas lentes tanto do narrador quanto do personagem, que, ao mesmo tempo em que conecta as duas vozes, aponta para a distância entre elas. É nele que "[h]abitamos, simultaneamente, a onisciência e a parcialidade." (WOOD, 2012, p.23).

Ele, então, passa a abordar diversos exemplos de indireto livre e aponta como refinamento do estilo a ironia do autor, que seria quando temos a impressão de que a distância entre as duas vozes desaparece e de que a voz do personagem está presente em toda a narração. Porém, também considera que é importante, para entender o estilo indireto livre, ver alguns casos em que ele não é conduzido corretamente.

\section{O deslize}

Nesse sentido, Wood (2012) mostra o que, para ele, é um deslize no discurso indireto livre: o acréscimo de explicações que seriam óbvias ao personagem. Ele usa o exemplo da apresentação do protagonista em um romance ("Terrorista", de John Updike), em discurso indireto livre. Nela, o jovem está caminhando e pensando no quanto cresceu, que não cresceria mais nesta vida e nem em uma outra, o que desencadeia uma reflexão sobre a visão islâmica do paraíso. Segundo Wood, esse pensamento sobre outra vida estava ali só para que o autor pudesse falar sobre essa visão, o que afasta o leitor da voz do personagem e mostra marcas do autor (ou, o que nos parece mais preciso: do narrador). Em especial, Wood chama a atenção para um momento em que, ao comentar uma ideia específica, há a menção da sura exata do alcorão em que ela estaria. Para ele, essa identificação exata não ocorreria se fossem as palavras do personagem, pois "[...] ele saberia onde está a passagem e não precisaria se lembrar dela." (WOOD, 2012, p.36). Ele completa, em nota de rodapé:

Imagine um rapaz cristão praticante andando na rua, e o texto dizendo algo assim: 'E Sua vontade não se faria para sempre, como está descrito na quarta linha do pai-nosso?'. O estilo indireto livre existe justamente para contornar a falta de jeito. (WOOD, 2012, p.36, grifos do autor). 
Ou seja: naquela tensão característica do discurso indireto livre, em que não é possível identificar quem está falando, o acréscimo de explicações que seriam óbvias para o personagem causa um desequilíbrio, fazendo sobressair a voz do narrador.

Vemos, na leitura de Wood, que essas explicações podem acontecer já na própria escrita da obra em indireto livre. Porém, neste trabalho, propomos a observação de mais uma camada: a da tradução.

\section{A estratégia}

Para além da mediação entre contexto de partida e o leitor do texto de partida, que, como já vimos, pode levar a alguma explicação, na tradução, temos a mediação com o leitor do contexto de chegada, que tende a ser mais distante do contexto original da obra do que aquele do original. Diversos autores apontam que o acréscimo de explicações é uma estratégia observada em tradução. Trazemos aqui os trabalhos de Francis Henrik Aubert (professor na Universidade de São Paulo nas áreas de tradutologia, práticas profissionais da tradução, terminologia e linguística contrastiva), de Amparo Hurtado Albir (teórica de tradução, professora de tradutologia da Universidade Autônoma de Barcelona e coordenadora do grupo PACTE) e de Javier Franco Aixelá (professor do departamento de tradução e interpretação da Universidade de Alicante), com o objetivo de exemplificar o fato de que diversos teóricos abordam esse tipo de recurso.

De Aubert, trazemos “Modalidades de tradução: teoria e resultados”, publicado em 1998 na revista TradTerm. A proposta é um modelo de pesquisa tradutológica que analisa um corpus de acordo com modalidades de tradução com base nos procedimentos elencados por Vinay e Darbelnet, possibilitando a análise quantitativa da tradução. A ideia de ser baseado em corpus é interessante para demonstrar que as estratégias elencadas são observadas em traduções, e não apenas teóricas.

Entre as modalidades propostas, o autor apresenta a de explicitação, "[...] em que informações implícitas contidas no texto fonte se tornam explícitas no texto meta (por exemplo, por meio de aposto explicativo ou parentético, paráfrase, nota de rodapé, etc.) [...]" (AUBERT, 1998, p.107). 
Esse "aposto explicativo" aponta para casos como o abordado por Wood (2012).

De Hurtado Albir, trazemos o capítulo "Nociones centrales de análisis", que compõe o livro "Traducción y traductología: introducción a la traductología", publicado em 2001. O foco do livro é a disciplina de tradutologia, recuperando o percurso do seu desenvolvimento ao longo do tempo, as pesquisas realizadas, noções centrais (como o nome do capítulo em questão sugere), entre outros aspectos.

Neste capítulo em específico, Hurtado Albir (2001) retoma noções que, tradicionalmente, fazem parte dos estudos de tradução, como fidelidade e equivalência, e faz a distinção entre método (a escolha global do texto), estratégia (guia o caminho para a solução) e técnica de tradução (representa a solução em si), sempre apontando diversas perspectivas de cada um. A partir disso, propõe técnicas de tradução. Para este estudo, interessa a de amplificação, em que "[s]ão introduzidas explicações não formuladas no texto original: informações, paráfrases explicativas, notas do tradutor, etc." (HURTADO ALBIR, 2001, p.269, tradução nossa). ${ }^{1}$ De novo, vemos a ideia do acréscimo de informações por parte de quem traduz.

De Aixelá, trazemos o texto "Culture-specific items in translation", publicado em 1996, como capítulo do livro Translation, power, subversion, editado por Román Álvarez e M. Carmen-África Vidal. O livro parte do princípio de que a língua não é neutra, e que, portanto, a tradução também não o é. A questão de poder indicada no título do livro, mais especificamente de um equilíbrio instável de poder entre as duas culturas envolvidas em determinado processo tradutório, está já no início do capítulo de Aixelá (1996). Para ele, esse equilíbrio vai depender de como o peso da cultura exportadora é percebido pela cultura importadora, aquela que vai tomar as decisões sobre a tradução. $\mathrm{O}$ autor aponta que a tradução precisa lidar com quatro áreas, basicamente: diversidade linguística, diversidade interpretativa, diversidade pragmática ou intertextual e, finalmente, diversidade cultural, que vai ser o foco do debate dele.

$\mathrm{O}$ autor desenvolve o argumento de que, com as diferenças culturais, a cultura de chegada deve escolher entre diversas estratégias para lidar com essa outra cultura, e que essa escolha vai demonstrar o grau de tolerância da cultura de chegada. Ele menciona que o ocidente teria uma tendência a

1 "Se introducen precisiones no formuladas en el texto original: informaciones, paráfrasis explicativas, notas del traductor, etc." 
adaptar os textos, aumentando a aceitabilidade na cultura de chegada, mas que, por outro lado, há um movimento de "[...] internacionalização cultural focada no polo anglo-saxão.” (AIXELÁ, 1996, p.54, tradução nossa), ${ }^{2}$ aumentando a familiaridade com essa cultura e a aceitabilidade dela.

Ainda que mostre que essas tendências podem variar de acordo com o tempo e com o contexto, Aixelá diz que "[p]arece lógico pensar que o sistema exportador tenha uma posição hegemônica em relação ao importador, o que leva à importação massiva de itens culturais [...]" (AIXELÁ, 1996, p.55, tradução nossa). ${ }^{3}$ Mas ele chega a um paradoxo, já apontado por outros autores, de que haveria uma tendência a domesticar os aspectos linguístico e pragmático, que seriam mais estruturais, mas de exotizar o sociocultural, que seria representado por aspectos mais "superficiais". A partir daí, Aixelá (1996) passa a tentar definir os itens culturalmente marcados para analisá-los especificamente, sem que sejam confundidos com os linguísticos ou pragmáticos.

Fazendo menção a Snell-Hornby, Aixelá define os itens culturalmente marcados como algo que não existe por conta própria, mas que "[...] cria um problema de tradução pela não existência ou pela diferença de valor (seja determinado por ideologia, uso, frequência, etc.) de certo item na cultura da língua de chegada." (AIXELÁ, 1996, p.57, tradução nossa). ${ }^{4}$ Portanto, os itens culturalmente marcados são identificados de acordo com os pares linguísticos de cada caso. Aixelá (1996) propõe duas categorias (substantivos próprios e expressões comuns), sendo que ele faz a ressalva de que a escolha por "expressões comuns" se dá pela falta de termo melhor para tratar do que não poderia ser incluído na primeira categoria.

Aixelá (1996) sugere, então, estratégias para lidar com esses itens, reconhecendo que os tradutores podem usar mais de uma delas no mesmo texto, sendo que se, por um lado, há fatores textuais que serão decisivos na escolha de cada caso, por outro, há a regularidade das escolhas, que será o elemento relevante e representativo do texto. $\mathrm{O}$ autor divide as estratégias em dois grandes grupos: conservação e substituição. Entre as estratégias do primeiro grupo estão a de nota extratextual e a de nota intratextual. Neste

\footnotetext{
2 "[...] cultural internationalisation focused on the Anglo-Saxon pole."

3 "It seems logical to think that the exporting system stands in a position of hegemony over the importing one, which entails the massive importing of cultural items $[\ldots] "$

4 "[...] poses a translation problem due to the nonexistence or to the different value (whether determined by ideology, usage, frequency, etc.) of the given item in the target language culture."
} 
trabalho, a atenção se volta para as notas intratextuais, que, na definição dele, englobam casos de explicações acrescentadas no corpo do texto, como o recurso apontado por Wood (2012).

O trabalho de Aixelá (1996) interessa especialmente para este trabalho, pois, além de apresentar a explicação como uma estratégia válida, traz essa proposta de que há itens que, em determinadas relações tradutórias, representam desafios especiais. Parece possível considerar que itens em outras línguas, que não a central do romance, possam ser entendidos como itens culturalmente marcados. No caso em questão, temos palavras em, por exemplo, africâner e francês, que certamente têm relações diferentes com o inglês e com o português (e, mais especificamente, na África do Sul e no Brasil).

Dessa forma, vemos que o acréscimo de explicações está previsto como abordagem possível no processo tradutório, conforme apontado pelos autores. $\mathrm{Na}$ tradução analisada aqui, diversas estratégias foram observadas e, entre elas, a de nota intratextual. Mostraremos o uso dessas notas em maior detalhe a seguir.

\section{0 caso}

Disgrace é um romance de J. M. Coetzee ambientado na África do Sul e narrado em terceira pessoa, com predominância de discurso indireto livre. O narrador é muito próximo do personagem principal, David Lurie, representando a tensão descrita por Wood (2012): em geral, é difícil separar uma voz da outra, e a perspectiva da narrativa parece refletir a do personagem (ainda que, em alguns momentos, como mostrado aqui, a tensão se desfaça). Lurie é um professor universitário da Cidade do Cabo que, após apresentar comportamento abusivo em relação a uma aluna (Melanie), sai da Cidade do Cabo e vai para a província do Cabo Oriental, onde mora sua filha, Lucy. Ao longo da história, escrita majoritariamente em inglês, vemos o uso de palavras e trechos (que consideramos aqui como itens culturalmente marcados) em outras línguas. Enquanto Lurie está na Cidade do Cabo, os itens são, na grande maioria, de línguas europeias. 
Quando o cenário muda, passam a figurar com mais frequência, também, itens em línguas oficiais da África do Sul, como africâner e xhosa.

Pela voz narrativa, muito próxima da perspectiva de Lurie, vemos um posicionamento dele como diferente das pessoas do Cabo Oriental, e essa diferença é também expressa em termos linguísticos. Trago dois exemplos desse posicionamento. O primeiro é um trecho em que Lurie confronta Petrus, personagem próximo a Lucy, sobre o envolvimento dele com um ataque que ocorre na casa de Lucy. É uma fala de Lurie seguida pelo comentário do narrador: “[...] Não é assim que nós fazemos as coisas.'[ ] Nós: ele está a ponto de dizer, Nós, ocidentais." (COETZEE, 2009, p.227-228, grifos do autor). Esse trecho demonstra que Lurie se vê como representante de uma cultura ocidental em oposição àquela do contexto do Cabo Oriental.

O segundo é, na realidade, em um momento anterior, nesse ataque. Nele, vemos uma reflexão sobre as línguas reforçando esse distanciamento:

Ele fala italiano, fala francês, mas italiano e francês de nada lhe valem na África negra. Está desamparado, um alvo fácil, um personagem de cartoon, um missionário de batina e capacete esperando de mãos juntas e olhos virados para o céu enquanto os selvagens combinam lá na língua deles como jogá-lo dentro do caldeirão de água fervendo. (COETZEE, 2009, p.111)

Esse trechomostra que aslínguas estãovinculadas ao posicionamento que é estabelecido entre Lurie e os outros personagens, e, portanto, não são usadas ao acaso ao longo da narrativa. Como já mencionamos, elas podem ser consideradas itens culturalmente marcados, já que remetem a significados diferentes no contexto de partida e no de chegada. Além disso, vemos, nesse trecho, um exemplo do que Moretti (2003) indica no indireto livre como compromisso social, usado para mostrar as tensões entre o que é posto como África branca e África negra. Temos a voz individual de Lurie misturada com o tom do narrador, gerando a voz intermediária mencionada por Moretti (2003), revelando o distanciamento que Lurie vê entre si e aquele contexto.

O texto de chegada é, como já mencionado, Desonra, de José Rubens Siqueira. Trazemos aqui os casos de nota intratextual no discurso indireto livre na tradução para análise. 
Tabela 1 - Notas intratextuais no discurso indireto livre na tradução

\begin{tabular}{|c|c|c|c|}
\hline $\begin{array}{l}\text { Texto de partida } \\
\text { (COETZEE, 1999, grifos } \\
\text { do autor) }\end{array}$ & $\begin{array}{l}\text { Texto de chegada (COETZEE, } \\
\text { 2009, grifos do autor) }\end{array}$ & Língua & Voz \\
\hline $\begin{array}{l}\text { Her accent is glaringly } \\
\text { Kaaps; it is Melanie (p.24) }\end{array}$ & $\begin{array}{l}\text { Ela carrega no sotaque kaaps, } \\
\text { típico da Cidade do Cabo; é } \\
\text { Melanie.(p.31) }\end{array}$ & Africâner & Lurie \\
\hline $\begin{array}{l}\text { On their right are an old } \\
\text { Afrikaner couple whom } \\
\text { Lucy greets as Tante Miems } \\
\text { and Oom Koos, and a little } \\
\text { assistant in a balaclava cap } \\
\text { who cannot be more than } \\
\text { ten. (p.71) }\end{array}$ & $\begin{array}{l}\text { À direita, um velho casal } \\
\text { afrikaner que Lucy cumprimenta } \\
\text { chamando de tia e tio, Tante } \\
\text { Miems e Oom Koos, e um } \\
\text { pequeno assistente que não deve } \\
\text { ter mais de dez anos, com um } \\
\text { boné de lã na cabeça. (p.83) }\end{array}$ & Africâner & Lucy \\
\hline $\begin{array}{l}\text { Just like the old days: baas } \\
\text { en Klaas. (p.116) }\end{array}$ & $\begin{array}{l}\text { Exatamente como nos velhos } \\
\text { tempos: baas en Klaas, um } \\
\text { "supervisor". (p.134) }\end{array}$ & Africâner & Lurie \\
\hline $\begin{array}{l}{[\ldots] \text { but particularly for }} \\
\text { pills, which they sell to } \\
\text { muti shops or trade in the } \\
\text { streets. (p.145) }\end{array}$ & $\begin{array}{l}{[\ldots] \text { mas principalmente }} \\
\text { comprimidos, que vendem nas } \\
\text { lojas muti, de negros, ou nas } \\
\text { ruas. (p.165) }\end{array}$ & Xhosa & Lurie \\
\hline $\begin{array}{l}\text { Sunt lacrimae rerum, et } \\
\text { mentem mortalia tangunt: } \\
\text { those will be Byron's words, } \\
\text { he is sure of it. (p.162) }\end{array}$ & $\begin{array}{l}\text { Sunt lacrimae rerum, et mentem } \\
\text { mortalia tangunt. Há lágrimas } \\
\text { para tudo, e as coisas humanas } \\
\text { tocam o coração: essas serão as } \\
\text { palavras de Byron, disso ele tem } \\
\text { certeza. (p.184) }\end{array}$ & Latim & Lurie/Byron \\
\hline $\begin{array}{l}\text { He brings in the gas stove } \\
\text { to make tea or warm up } \\
\text { canned food: spaghetti } \\
\text { and meatballs, snoek and } \\
\text { onions. (p.211) }\end{array}$ & $\begin{array}{l}\text { Traz o fogão para fazer chá e } \\
\text { esquentar comida enlatada: } \\
\text { espaguete e almôndegas, snoek, } \\
\text { peixe seco e cebola. (p.238) }\end{array}$ & Africâner & Lurie \\
\hline $\begin{array}{l}{[\ldots] \quad \text { though Bev Shaw }} \\
\text { refers to it as Driepoot) }[\ldots . .] \\
\text { (p.215) }\end{array}$ & $\begin{array}{l}{[\ldots . .] \text { (embora Bev Shaw refira-se }} \\
\text { a ele como Driepoot, três patas) } \\
{[\ldots] \text { (p.241) }}\end{array}$ & Africâner & Bev Shaw \\
\hline
\end{tabular}

Fonte: adaptado de DIAS (2018).

As vozes do discurso indireto livre em tradução 
Vemos aqui, portanto, casos de explicações adicionadas no corpo do texto no discurso indireto livre. No primeiro caso, Lurie está assistindo ao ensaio da peça em que sua aluna Melanie está atuando. Há um comentário sobre o sotaque "kaaps" de Melanie e, na tradução, temos mais informações sobre ele, localizando-o como referente à Cidade do Cabo. No segundo, Lurie está chegando com sua filha, Lucy, no mercado onde ela expõe o que produz, e eles encontram um casal conhecido de Lucy. Vemos também mais da relação de Lucy com o casal, descobrindo que "Tante" e "Oom" significam tia e tio.

Adiante, Lurie vai de novo ao mercado, dessa vez sem Lucy, mas com Petrus. Somos apresentados à visão que Lurie tem da relação entre ele e Petrus naquele contexto, "baas en Klaas", explicitada (e possivelmente suavizada) com "um supervisor". Lurie, em outro ponto da história, passa ajudar em um refúgio de animais e a levar os que morrem para a incineração, onde vê o destino dos resíduos do hospital, como os comprimidos, que serão coletados e vendidos em lojas "muti", que são descritas como "de negros" no quarto caso.

O quinto caso mostra Lurie decidindo a fala de um dos personagens, Byron, na ópera em que está escrevendo. A fala, em latim, ganha uma tradução. Mais para o final do romance, há a descrição de uma refeição de Lurie, com "snoek", explicado como "peixe seco". O último caso que vemos é de descrição da relação de Lurie com um dos cachorros do refúgio, que tinha três patas, e do modo como Bev Shaw, a responsável pelo refúgio, o chama ("Driepoot", que ganha a explicação).

É nesses momentos que, segundo Wood (2012), a tensão entre a voz do narrador e a do personagem se desfaz, transparecendo só a do narrador. A maioria dos casos é referente ao contexto do Cabo Oriental, à exceção do caso de "kaaps", que está no contexto da peça em que a aluna de Lurie atua (ainda na Cidade do Cabo), e "Sunt lacrimae rerum (...)", que está no contexto da ópera que Lurie está escrevendo.

Por mais que haja o já mencionado movimento de distanciamento de Lurie em relação ao contexto do Cabo Oriental, ele entende aquelas palavras em africâner e xhosa, de acordo com a perspectiva de Wood (2012). Se não entende (o que é especialmente possível nos casos em que menciona o que Lucy e Bev Shaw dizem, com "Tante", "Oom" e "Driepoot"), também não demonstra a necessidade de buscar alguma explicação. No caso do 
latim, se está optando por usar aquela frase na ópera que está escrevendo, sabe o que ela significa. Então, podemos considerar que as explicações não partem dele. Quando há o acréscimo de explicação, ali se revela, portanto, o narrador. Mais do que isso, é o narrador da tradução, e não o narrador do texto de partida, que acrescenta aquelas explicações. Assim, podemos pensar que é uma voz da tradução que é acrescentada.

Vemos que o narrador do texto de partida também usa recursos semelhantes em alguns casos, como em "[a] peasant, a paysan, a man of the country." (COETZEE, 1999, p.117, grifos do autor), que é traduzido como "[u]m camponês, um paysan, um homem do campo." (COETZEE, 2009, p.136, grifos do autor). Não chega a ser um acréscimo de explicação explícito, mas é uma busca por uma palavra específica, que acaba explicando o significado da palavra que não estava em inglês (ou português, na tradução). Ou seja: talvez o leitor não saiba o que é "paysan", mas vai reconhecer "peasant" ou "camponês" e entender que o sentido é semelhante. Nesses casos, essa busca é traduzida, e o item culturalmente marcado, mantido. Assim sendo, o leitor já conhece esse recurso de explicações intratextuais, e, assim, a escolha do acréscimo de explicações no corpo do texto na tradução pode não destoar do resto do texto (lembrando a proposta de regularidade trazida por Aixelá (1996)) e demonstra ser uma estratégia válida. O que buscamos mostrar aqui é que, na tradução, ainda outras explicações podem ser acrescentadas, e, portanto, haveria mais momentos de suspensão da tensão entre as vozes do narrador e do personagem do que no texto de partida.

\section{Considerações finais}

Analisamos, aqui, um caso em que a "voz narrativa local", da proposta de Moretti (2000), conta com a voz em discurso indireto livre, o que levou à observação de dois aspectos principais, um em relação à técnica e outro em relação ao que ela representa.

Composta pela tensão entre a voz do personagem e a do narrador, é preciso considerar que, em alguns momentos, essa voz dá um passo para trás e se afasta do contexto local para fazer a mediação com o leitor. 
Pensando que, nesses momentos, a tensão se desfaz e a voz do narrador se sobressai, podemos considerar que, aí, essa voz narrativa se subdivide, e, portanto, esse ponto da conciliação de Moretti (2000) pode ser visto como sendo composto por duas vozes. Quando somadas na análise as traduções, uma dessas vozes passa a ser a voz narrativa da tradução nos momentos em que é ela que acrescenta alguma explicação para o leitor do texto de chegada. Essa voz, no entanto, só pode ser identificada em cotejo, especialmente se a voz narrativa do texto de partida já trouxer explicações, conforme demonstrado aqui.

Para além da tensão entre a voz do narrador e a do personagem, há aquela entre a subjetividade e a racionalização. Neste romance, ela representa a tensão entre Lurie, que se vê como representante de uma África branca, ocidental, e o contexto em que se encontra (em especial, fora da Cidade do Cabo), que ele entende como África negra.

A análise do romance de Coetzee e de sua tradução demonstra uma complexificação dos termos propostos por Moretti (2000). Sob uma perspectiva macro, o discurso indireto livre tem no romance uma função de mostrar as tensões entre África branca e negra, ou seja, mostra a racionalização das relações pessoais, como apontado por Moretti (2003). Sob uma perspectiva micro, o triângulo formado por enredo, personagens e voz narrativa tem mais um vetor, a voz do tradutor.

\section{Referências}

AIXELÁ, Javier Franco. Culture-specificitems in translation. In: ALVAREZ, Rodriguez; VIDAL, María del Carmen-África. (ed.) Translation, power, subversion. Philadelphia: Multilingual matters, 1996. p. 52-78.

DIAS, Cecília Fischer. O posicionamento do protagonista David Lurie em Disgrace e Desonra pelo uso de diferentes línguas na narrativa. Orientador: Ian Alexander. 2018. 50 f. TCC (Graduação) - Bacharelado em Letras, Instituto de Letras, Universidade Federal do Rio Grande do Sul, Porto Alegre, 2018. 
AUBERT, Francis Henrik. Modalidades de tradução: teoria e resultados. TradTerm. São Paulo, v. 5, n. 1, p. 99-129, jun. 1998.

COETZEE, John Maxwell. Disgrace. Londres: Vintage, 1999.

COETZEE, John Maxwell. Desonra. Tradução de José Rubens Siqueira. 3. ed. São Paulo: Companhia das Letras, 2009.

HURTADO ALBIR, Amparo. Traducción y traductología: Introducción a la Traductología. Madrid: Ediciones Cátedra, 2001.

MORETTI, Franco. Conjeturas sobre a literatura mundial. Tradução de José Marcos Macedo. Novos Estudos CEBRAP, São Paulo, n. 58, nov. 2000. Disponível em http://novosestudos.com.br/produto/edicao-58/. Acesso em: 17 jun. 2021.

MORETTI, Franco. O século sério. Tradução de Alípio Correa e Sandra Correa. Novos Estudos CEBRAP, São Paulo, n. 65, mar. 2003. Disponível em http://novosestudos.com.br/produto/edicao-65/. Acesso em: 17 jun. 2021.

WOOD, James. Como funciona a ficção. Tradução de Denise Bottman. 1. ed. São Paulo: Cosac Naify, 2012. 